\title{
Operative strategies of HLB's scouts of a ci- trus property within the State of Sao Paulo, Brazil
}

\author{
Glaucia Helena Gonçalves $^{\mathrm{a}^{* *}}$, Nilton Luiz Menegon ${ }^{\mathrm{a}}$ \\ ${ }^{a}$ Production Engineering Department, Federal University of São Carlos, Rodovia Washington Luís, km 235, São \\ Carlos- SP, Brasil
}

\begin{abstract}
This research aimed to study the activity of the HLB's scouts, workers whose function is to identify symptomatic plants, in order to understand the physical constraints, cognitive and organizational involved in accomplishing the task, characterizing the operative approach used to identify diseased plants, and to elucidate what aspects hinder the identification of symptoms.

The method adopted for the research was the Ergonomic Analysis of Work - EAW [6].

The results, after validation with the operators and management, allowed understanding the complex relationships between the physical, cognitive and organizational aspects present on activity.

Major difficulties were observed mainly in relation to the disposal of the scouts on the platforms and in relation to working hours, at the beginning and end of the journey. Important findings have highlighted strategies, unknown by the organization, used by scouts to locate candidates' trees to the fine analysis of investigation of symptoms.

In conclusion, the analysis enable to understand the constraints and find technical and organizational solutions to the survey work on citrus groves as well as it showed signs and symptoms not investigated yet or rarely considered by researchers involved on searches aimed at increasing the ability to diagnose the disease in the field.
\end{abstract}

Keywords: Activity analysis, ergonomics, HLB, greening, survey.

\section{Introduction}

The Brazilian orange growers have faced a difficult problem to solve. This is huanglongbing-HBL, known as HLB, a disease that spreads rapidly and is highly destructive to citrus groves. It is associated with a decline of citrus trees and possesses a great potential of affect citrus trees of all cultivations and cause great damages to the citrus industry by shortening the productive life span of tress.

In Brazil, the largest citrus growing in the world, symptoms of citrus HLB were first recognized in March 2004 on sweet orange trees near the city of Araraquara in São Paulo State (SPS), but it has already known in other Asian countries, African and more recently in the United States. It was presumed to originate in China during the 1919 as a "yellow shoot disease" [1]. African HLB was first in 1929 $[10,12]$. In USA, the second growing region, the disease was recognized just in August 2005. The HLB is considered the most destructive disease of citrus worldwide and represents a major threat to the world citrus industry [9]. By 2008, three million symptomatic trees were eradicated, resulting in losses of 5.5 million boxes of oranges a year, which roughly corresponds over US\$ 91 million for the growers producers. The impact of these losses is even higher to the orange juice industry [8].

The HLB disease is caused by a phloem-limited bacterium, as Candidatus Liberibacter ssp. In Brazil,

\footnotetext{
* Corresponding author. E-mail: Glaucia@dep.ufscar.br
} 
the bacterium is transmitted by psyllid insect Diaphorina citri, a small gray insect with dark spots on their wings, which measures two to three millimeters in length. D. citri is common in Brazil and it has been presented for more than 50 years in orchards and ornamental plant known as myrtle, false myrtle or myrtle smell, whose scientific name is Murraya paniculata. Infected trees show a blotchy mottle condition of the leaves that results in the development of yellow shoots, the early and very characteristic symptom of the disease (Figure 1A). In some cases, there is thickening and whitening of leaf veins. With the evolution of the disease, there is a decay of the affected leaves and transmission to other branches. The fruits have a reduction in size and become deformed and asymmetric due to the difference of maturation (Figure 1B), because one side can mature before the other. It can be observed small light green circular patches in their skins that contrast with the natural color of the fruit (Figure 1C). It is common an occurrence of aborted seeds, malformed and dark coloration. An intense fruit drop and damage to the flavor can also occur. The symptoms of HLB are very similar to the symptoms of nutritional deficiency (deficiency of zinc, magnesium, manganese, copper) and diseases (citrus variegated chlorosis and buds), which complicates the identification and diagnosis. $[2,5,8]$

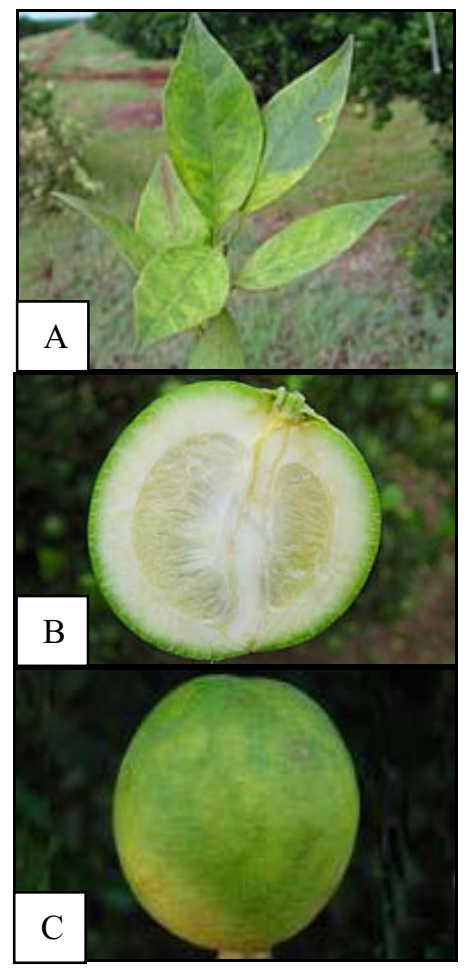

Fig.1: A: Illustration of the disease's signs on the leaves. B and C: Illustration of the signs of the disease on fruit.
There are no curative methods to control HLB and different management strategies are needed to avoid a potential threat of HLB disease. Some measures recommended [5] involve: (i) Getting healthy seedlings produced in nurseries covered, insect proof screen houses, following the phytosanitary legislation, to ensure that the seedlings are not contaminated, hence do not perpetuate the disease; (ii) Providing vector control with the application of insecticides; (iii) Eliminating the myrtle trees which serve as host for the psyllid and the bacterium; (iv) Identifying infected trees as soon as they expresses the first symptoms and removing them to do not serve as a source of inoculums, such determined compulsory by law in Sao Paulo State (SPS).

The fact that the vector is a flying insect has as consequent high spread of the disease. Treatments with contact and systemic insecticides reduce psyllid populations, and thus HLB spread. However, beyond not been enough to solve the problem, it leads to serious ecological problems of resistant insects to used pesticides and reduce populations of insects, such as bees, essential for pollination of many plants [8].

In practice, removal of infected trees is made by surveys to identify symptomatic ones. Visual assessment of survey still is the most economical and efficient method on disease control [7]. Bové [1], in report experience in a large grove (one million trees) in southern China, suggests that the scouts in charge of the surveys should work in pairs, so that each tree is examined by the two scouts of a pair, one scout on each side of the row. In the case of orchards with large, adult trees, it is essential to examine the top of the trees. In SPS, relatively high towers have been built onto tractors to permit efficient observation of tree tops. Finally, once affected trees have been identified, they should be removed as quickly. Nevertheless, researches have shown that surveys invariably fail to identify sick plants [[11]]. It is estimated that visual surveys fails approximately 30 to $60 \%$ on identifying infected plants, because it can be mistaken for other diseases or nutritional deficiency [8]. In addition, there is a latency period during which recently infected trees do not show symptoms. This period extends from the moment the tree becomes infected by the psyllid up to the moment it expresses symptoms, about six to twelve months [1]. This means that when the first symptoms show up, the infection actually has occurred months ago. During this latency period, the asymptomatic diseased plant acts as a focus, spreading HLB to the healthy trees around [8]. 
It is, therefore, the toughest challenge for the citrus growers and for the "Greening scouts," which are workers who have the function to identify diseased plants in the orchards. The difficulties in identifying early stages infections of HLB and its severity constrain the work of scouts.

In this context, this article focuses on examining the activity of HLB's scout, understanding the constraints of physical, cognitive and organizational issues involved in accomplishing of the task, characterizing the operative strategies used to identify diseased plants, and elucidating which aspects hinder the identification of symptoms.

\section{Methods}

Understanding and studying the problems of this research involve interacting with the environment in which the survey activity takes place, internalizing problems and understanding the situation's different points of view. In this context, it is appropriate the ergonomic analysis of work - EAW proposed by authors as Guèrrin [6], Wisner [14] and Daniellou [3], that starts from research activity to compose their studies. This methodological approach was chosen in this study because it is a demand that could not be understood only by the prescriptions of the job. Besides, it is a problem that requires the exploitation of workers' experience and knowledge in their activities.

The EAW is divided into a set of steps, not necessarily linear, but linked to each other. These steps guide the ergonomic action, designated: Analysis of demand, collecting information about the company, the population characteristics' survey, choices of analysis' situations, analysis of the technical task, and opened and global observations of the activity, preparation of pre-diagnosis, systematic observations (analysis data) and validation. These stages are present in this study.

The initial demand of this research arose from a problem facing by the citrus industry in São Paulo State: the difficulty of early identification of sick plants in the context of the orchard and the problem of inaccuracy of the survey, culminating in "leaks" which are plants with symptoms of the disease that are not detected in surveys.

From the initial demand, it was clarified that the analysis would focus on the activity of HLB survey. For this, a partnership with a citrus production unit located in the city of Matão/SP, which works with HLB survey teams into platforms for disease control, was established.

The analysis for this research began in December 2009 and it has continued until January 2011. The progress of the steps of ergonomic analysis of work had a large number of visits to the farm. The average is of one visit every two weeks, a total of 18 field visits and five office visits.

In order to understand the demands of the research, tasks and activity, the analysis began from the monitoring of survey teams at work, on which observations were made about the behavior of scouts, and monitoring the administrative environment for data acquisition of the company and workers.

The first visits took place in the office of citrus property. They sought more formal information and clarifications on the framework for workers, company data, hierarchies, ways to organize, wages, bonuses, benefits and other relevant matters. The analysis continued in the field, with surveys workers, following them from the beginning to the end of the journey. The activity was recorded with the aid of cameras, video cameras and voice recorders to allow more accurate and detailed analysis. To better elucidate the visual strategies, workers were equipped with survey glasses equipped with digital camera in order to understand the mechanisms of observation and perception of disease symptoms. The research also has used open individual and group interviews, semi-structured individual interviews and closed interviews.

After better understanding of the task and demand, it was sought to uncover the operational methods and individual and collective strategies used by scouts to meet the objectives of the work. Thus, this study set out to return the results to scouts in self confrontation interviews. There were two meetings of this nature, in which it was possible to confirm some findings, to challenge others and to face unverified information above.

In response to these self-confrontation meetings were also organized meetings with management and involved professionals to enrich the discussion and raise other points of view. Thus, these latter meetings focused on discussions about solutions and improvements for activity.

\section{Constraints and Strategies of Scouts HLB}

In this article, we chose to emphasize the results more closely related to the activity to seek and confirm the symptoms in citrus plants. Therefore, important aspects of the task will be clarified to allow interlacement with the analysis of the activity. 


\subsection{Prescribed work of the scouts}

The effective population of workers studied on the visual survey of HLB was composed by 55 scouts. Each worker, on the platform, inspects an average of 1,750 plants per working day period in $8 \mathrm{~h} 48 \mathrm{~min}$. This population consists of $100 \%$ male. Of these, $21.72 \%$ are aged 20 to 30 years, $30.77 \%$ from 31 to 40 , and $25.35 \%$ from 41 to $50,14.48 \%$ from 51 to 60 , and $7.24 \%$ from 61 to 70 . Regarding the level of education, it was found that $5.43 \%$ are illiterate, $70.59 \%$ have incomplete primary education, $1.81 \%$ has completed elementary education, $3.62 \%$ have incomplete secondary education, $16.29 \%$ have complete high school and $1.81 \%$ has incomplete higher education.

The journey of the scouts occurs Monday through Friday, for a total of eight hours and forty-eight minutes a day to complete 44 hours per week. The scouts must begin the journey at 07:00 and conclude until 16:48. The beginning of the survey activity depends on the distance between the place of arrival, called "California", and the location in which the team will be allocated for survey. Except for some teams, whose hours actually starts closer to 07:00, because they have no need to go until "California" and they addressed directly to the survey location. All teams, regardless of place of arrival, perform gymnastics at 07:00.

The scouts make a break for lunch from 11:00 to 12:00. At 14:00, they accomplish labor gymnastics at the place where they are performing the survey for the second time of the day.

On Saturdays, some workers may be required to work. In this case, usually it is called who has late hours in the bank of hours and need to be replaced because the farm does not pay overtime.

The scouts of HLB of this farm have the function of survey of citrus plants on platforms attached to a tractor, which can be double (Figure 2) or simple (Figure 3).

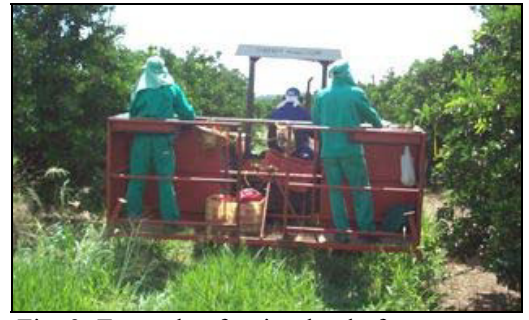

Fig. 3: Example of a simple platform survey.

The survey is defined as: identifying plants with suspicious symptoms of HLB within a reasonable distance, requesting to stop the tractor, to move closer to the plant to evaluate suspicious ones, and tying a yellow plastic ribbon that helps identifying the sick plant in case of confirmation, or to continuing the survey in case of suspicion refuted.

Surveys must meet work goals established by the direction that follows the conformation of the Table 1.

Table 1

Meta survey by platform

\begin{tabular}{lrl}
\hline Type & $\begin{array}{c}\text { Goal (plants per machine per } \\
\text { day) }\end{array}$ \\
\hline Simple Platform & 5000 & \\
Dual Platform & 3500
\end{tabular}

Once hired for the survey, scouts must be trained. In this training, they are first presented, at least, to a plant infected by HLB to make symptoms clear. Then, the new scout follows the team of four people on the platform or surveys on foot, trying to identify plants with symptoms of HLB and watching those found by the team. This period of field training can last about 15 days or longer if necessary. After that, the scout takes his survey place and goes to work like the others, despite not being fully confident about the symptoms of the disease.

\subsection{Problems and difficulties of survey activity}

According to the scouts, the variations of the sun are the factors that hinder the survey. They report that in the morning, between 7:00 and 9:00 am, and in the afternoon after 15:00, when the sun is down, it becomes more difficult to see the symptoms. In these periods, the sun disturbs the vision because of its rays being in horizontal position and reflect directly into the scouts' eyes.

Fig. 2: Example of dual-platform survey 
...all the plants that are found in crosschecking...the zone were usually inspected at 7:00 am or 9:00 am or after 3:00 pm...

Other difficulties in the survey would be in the plants with new vegetation. Its leaves clearer highlight itself among the trees such as the HLB leaves, calling attention of the scouts.

...ran the eye and saw that was new vegetation ... getting out...

The scouts also pointed the difficulties of seeing the symptoms in the space between a plant and another. According to them, symptomatic plants found in the crosschecking usually have the symptoms concentrated in this region, the gap between the plants and in the barred.

An important question about the difficulty of seeing the symptoms is the positioning on the platforms. It was seen and reported that, on the ground floor of the platforms, there are drawbacks that constantly disrupt the survey, such as: narrow streets that make the scouts spending most of their time deviating from the branches; and small visual field that restricts the possibility of full observation of the plant and restrain the possibility of anticipation of the survey. Scouts from the lower floor perform at end a secondary role in the survey platform. In most cases, the scouts placed on the top floor are who recognize symptoms in the whole plant, from the bottom to the top.

...the function of the two located downstairs is basically just to tie the ribbon...

...those who are usually on top... find more on the bottom than those who are downstairs...

According to scouts, around of 15:00, they feel more distracted because they are more susceptible to physical and mental fatigue. Some also report getting distracted after lunch, because sometimes feel sleepy.

Another debate is about the need to balance the "stops" to check the suspicious symptoms observed with the platform on moving.

...it has to fulfill the goals...if all yellowish branches viewed you ask for stop...in the end the day you don't make the target...

Still on this theme it was debated about the quality and quantity of service. According to the scouts, it may have been done a great job in a grove, with many plants identified, if you leave one behind, the team may lose bonus as well. ....we can make a grove and find 200 plants... tomorrow is the crosschecking... if you find a symptomatic plant there you will be punished the same way... ...you have found 200... but have left one...

3.3. Strategies used by the scouts of HLB

When asked about how to identify symptoms, workers report that they look for branches with yellowing leaves.

...yellow calls our attention...we always look where there is a yellow twig...our attention don't go to green...

However, in orchards where trees are covered with orange fruits, the scouts also note if there is fruits on odds with the healthy fruits. In this case, the scouts observe fruits deformed, crooked, withered, with yellowish or greenish gray, or if they presents maturing unlike the others, because they stand out among the plants.

...when the yellow branch is seen...what are we going to do to see whether it is or not is the Greening and ask to stop the tractor?...we will look for an orange...because the orange presents more symptom for us than the yellow branches...but in the first place we search for yellow branch ...

In case there is no fruit on the plant, they back to the symptoms of the leaves.

For the scouts, the presence of healthy fruits can also be an exclusion criterion for HLB. The scouts report that when arises a doubt about a branch, but is perceived the presence of ripe oranges and healthy, they dismiss the doubt.

...in the case of the plant being with many symptoms, the orange would have fallen...

Another feature of easy discrimination is the incident of the plant with leafless branches, which can be a symptom of HLB and facilitates the identification of HLB, although it is a late symptom.

It was also reported by some more experienced scouts that, it can be checked in leaves infected by HLB, an aspect cuspidal and steep.

... the branch of the HLB is different of the entire foot... ...it's a leaf hard and pointy...

...it seems that the HLB leaf is bristled...

Some even compared it with the look of a plastic leaf and that the leaves appear to retain less dirt. 


\section{...looks like plastic... ...holds less dirt....}

Another way appointed by the scouts to search for HLB symptoms is to anticipate the demand in two or three trees forward. Which means, instead of the scout seeing the trees on the side; he looks around two or three trees forward, because this increases the visual field and facilitates the survey.

...Another important thing is to inspect at a distance... because when farther from the plant... more overview you have...

This operating strategy facilitates the survey of the scouts, especially in platform surveys. Once viewed a suspect in a plant ahead, the scout has the opportunity and time to assess whether the issues that raised suspicion are enough to request a stop of the tractor.

...when he looks from afar... if it has any symptoms of the disease... a yellow twig...He'll see ...when get close to the plant he fixes his gaze to confirm... (Referring to the scout on the platform)

After viewing at distance the aspects mentioned, the scouts need to make sure that the observed features actually match with the symptoms of HLB. In this way, it is avoided marking plants mistakenly. For this, when on platform, it is requested stopping the tractor towards to approach the plant with suspicion. From this, the branch that stood out for the scout is searched and so it is examined whether there are leaves that present the typical symptoms of the disease such as mottling between green and yellow.

...this thing of having a lighter side and the other darker...other disease does not do...

A way used as an aid to ensure the presence of mottling on the leaf is put it against the sun.

... when you do not see the mottled ... puts against the sun that you can see better...

Confirmed the mottling in the plant, is analyzed in these branches if there is the presence of peeling or injured, occurrence of citrus pink disease ${ }^{1}$ or if there

\footnotetext{
${ }^{1}$ The citrus pink disease is caused by the fungus Erythricium salmonicolor. It affects citrus' twigs and branches and other plant species. Symptoms can be seen in the "armpits" of the branches on pink or white pustules form and irregular shape. Shell shows cracks or longitudinal disruptions. The fungus's growth prevents conduction of sap, causing wilting of leaves, death of limbo, yellowing and leaf fall [13].
}

is "Drill of orange" ${ }^{2}$, which could be hindering the transport of sap and therefore giving the appearance of symptoms similar to HLB.

Under uncertainty, the scouts press the fruit to see if they have a grayish color, which is also characteristic of HLB. Sometimes the fruit can also be cut to check out if there are symptoms not noticeable externally such as abortion of seed and asymmetry maturation. It was reported that in the site where the contaminated fruit are removed from the branch it is possible to see a reddish appearance at the insertion point.

According to the scouts, it is also possible to see a gray semblance in the leaves appearance of plants infected with HLB.

Collective strategies were observed between the teams. On step the suspicions are confirmed, there are times when the scout cannot resolve the question even if he shares with the team. In these situations, two behaviors were observed: one is to mark the plant with the tape, even without an answer, then later the appraiser that is of the eradication team, decides whether is HLB or not; other behavior is to leave the plant without tagging so that in a future survey, the survey team observes the symptoms progress.

Collective strategies were also found concerning the speed of the tractor. According to reports, the survey teams enter into an agreement and choose to act in the following way: when it is known that a grove is under greater suspicion of HLB, the truck driver moves on a slower speed so that the survey can be more effective and it is avoided leaving symptomatic plants behind. Still on the speed, the scouts commented that, as early in the morning and at the end of the day the sun disturbs the visualization of symptoms and due in the morning they feel a bit slow on the survey, they match with truck's driver to maintain lower speed in these periods, in order to provide higher quality of surveys.

\section{Analysis of results}

The analysis of results, after validation with the operators and management, enable to understand the intricate relationships between the physical aspects, cognitive and organizational present on activity.

\footnotetext{
${ }^{2}$ The Drill-of-orange, Cratosomus flavofosciatus, is caused by a beetle. The female makes a hole in the plant's trunk where it lays an egg. The egg's hatching releases a grub that blocks the trunk and thick branches. Signs' plague shows galleries and orifices that expel sawdust in pellet forms [9].
} 
The analysis allows seeing that there are two stages of identification of HLB: looking for the symptoms and confirming these symptoms.

The first step is considered the most important in this research, because such stage signals the potentials symptomatic plants and without it is not possible to move towards the second. For this step, there is no formal training because its importance is not recognized by the organization. The only formal knowledge established concerns about the instruction to look for "yellow twigs." However ask to stop the tractor for any yellow branch seen leads to many errors, or false suspicions. It could lead to failure to achieve targets set. This fact determines that the suitability for survey is necessarily given by the experience and knowledge acquired during the activity.

In this sense, we identified strategies used by scouts in order to locate candidates' trees to the fine analysis of investigation of symptoms, unknowns for the organization and by the scouts. It was found that the scouts are looking for a "yellow branch" in the visual field faraway, at two or three plants ahead on travel direction. After the twig is located, a plan of fine visual search is gone off like this: fruit defective, leafless branches, pointed leaf, as selection criteria of suspicion, as well as the occurrence of healthy fruits (in the branch candidate) as exclusion criteria. This strategy works concurrently with continuous rotation movements of the head and body to focus on the candidate tree, followed by decision-making described as stop or not stop the vehicle survey.

As a rule, to stop the vehicle and approach of the candidate tree puts into action the knowledge acquired in formal training, as well as tacit knowledge used for diagnosis of HLB. In the case of non-formal learning, such as grayish leaf, leaf that does not retain dirt, yellow and thick rib, leaf-looking plastic sheet, positioning against the sun, among others, reveal the importance of the experience of the scouts on the detection of HLB and, consequently, the conflicts with the eradication teams that focus on mottles as diagnostic criteria.

Lack of formal knowledge is evidenced by the fact that a new scout takes up to two months to feel safe to identify a plant with symptoms.

Other issues highlighted focus on perceived difficulties in relation to the disposal of the scouts on the platforms and in relation to working hours.

When sunlight disrupts considerably viewing and requires reducing the speed of transfer between plants at the beginning and end of the day, there is an impact on the quantity and quality survey. The problems of viewing and the incidence of sunlight led to reflection on the adequacy of survey schedules.
The problem with the diversion of the twigs and the small visual field led to rethink the concept of a new platform, positioning the operators in a suitable way to achieve a better visual field.

The issues brought to light by activity analysis also allow understanding the conflict between quality (do not let symptomatic plants inspected in the orchard) and quantity (3500 plants to inspect per day). The time of stop of the vehicle implies in non-survey of nearly 26 plants. The focus on candidate tree excludes from the center of visual attention on the neighbors' trees, which may also be contaminated.

\section{Conclusion}

The aspects highlighted in the analysis refer to: i) with respect to physical aspects and environmental highlights the inadequacy of the platforms and postural constraints of working on foot, leading to a new proposition of platform ii) in relation to organizational aspects, highlights the inadequacy of the survey schedule in the morning and evening due to the incidence of sunlight which leads to reconsider goals, rethink productive time and the development of glasses suitable for survey activity, and iii) in respect the cognitive aspects, highlights the inadequacy of the training processes that focus on confirmation of symptoms rather than the identification of candidate plants in the field.

Additionally, the analysis of the activity of HLB scouts not only enable to understand the constraints and find technical and organizational solutions to survey work of citrus groves, but also indicated the signs and symptoms not yet investigated, or rarely considered by researchers, who are involved on investigations that aim towards increasing the ability to diagnose the disease in the field. Such evidence may partially explain the differences of diagnostic between the survey teams and eradication. As scouts say: "It is still not Greening, but it will be one!"

\section{References}

[1] Bové, J.M. Huanglongbing: a destructive, newly-emerging, century-old disease of citrus. Journal of Plant Pathology, Pisa, v.88, n.1, p.7-37, 2006.

[2] Coelho, M.V.S.; Marques, A. S.D.A. "Citrus HLB": A quaternary bacterial which represents a potential threat to the Brazilian citrus industry. 2002. Available in $<$ http://www.cenargen.embrapa.br/publica/trabalhos/cot058.p df $>$. Accessed 19 January 2009.

[3] Daniellou, F.; Béguin, P. Action ergonomic methodology: approaches to real work. In: Falzon, Pierre. Ergonomics. Translation: INGRATTA, G.M.J. et al. São Paulo: Edgard Blücher, 2007. Chapter 20, p.281-301. 
[4] Department of Agriculture, Irrigation and Agrarian Reform. Orange Crop. Available at: http://www.seagri.ba.gov.br/Laranja.htm Accessed: 01 September 2011.

[5] FUNDECITRUS - Defense Fund citrus industry. HLB's Technical Manual. Available in $<$ http://fundecitrus.com.br/manuais.html $>$. Accessed 19 January 2009.

[6] GuèrrinN, F.; Laville, Daniellou, F.; Duraffourg, J.; Kerguelen, A. Understanding the work to transform it. São Paulo: Edgard Blücher, 2001. 200 p.

[7] Survey efficient: Surveys that use the platforms facilitate the detection work of HLB. Magazine Fundecitrus - Citrus Defense Fund, Araraquara-SP No 147, p. 14, Sept / Oct 2008.

[8] Milori, D. The citrus industry at risk - the nightmare of HLB. 2008. Available

\section{in} $<$ http://www.agrosoft.org.br/agropag/103543.htm>. Accessed 19 January 2009.

[9] Miinistry of Agriculture. Researchers draw up strategies to eradicate HLB in Brazil. 2008. Available at: http://www.canalrural.com.br/canalrural/jsp/default.jsp?uf $=1$ \&local=1\&action=noticias\&id=2019296\&section=noticias. Accessed: 03 March 2009.
[10] Oberholzer P.C.J., Von Staden D.F.A., Basson W.J. Greening disease of sweet orange in South Africa. In: KAPP J.K. Proceedings of 3rd Conference of the International Organization of Citrus Virologist. Gainesville, University of Florida 1965. p. 213-219.

[11] Red light in citrus. Agricultural Information Coopercitrus, SP- Bebedouro, No 260, p.16-24, Jun-2008.

[12] Roistacher, C.N. Techniques for biological detection of specific citrus graft-transmissible diseases. In: Roistacher C.N. Graft-transmissible Diseases of Citrus: Handbook for Detection and Diagnosis. Rome, 1991. p. 35-45.

[13] Souza, Fernanda Luiza de. Genetic variability of fungus Erythricium salmonicolor, causal agent of pink disease of citrus. 2006. 56p. Dissertation (Master's degree in agronomy) College of Agriculture Luiz de Queiroz, USP, Piracicaba, 2006.

[14] Wisner, Alain. Summary of task analysis. In : Inside job: Ergonomics: Method \& technique. Trad. Flora Maria Gomide Vezza. São Paulo: FTD, 1987, cap.14, p.113-119. 